\title{
The Qualitative Analysis of the Managerial Behavior Psychological Foundations in Iran's Higher Education
}

\author{
Mohammadali Kalantari ${ }^{* 1}$, Jalil Baharestan ${ }^{2}$, Mohammadali Nadi ${ }^{3}$ \\ 1. Department of Educational Management (PhD), Isfahan (Khorasgan) Branch, Islamic Azad University, Isfahan, \\ Iran; Mohammadkalantari.5337@yahoo.com " ${ }^{*}$ (corresponding author) \\ 2. Associate Professor, Department of Educational Management, University of Yazd, Yazd, Iran \\ 3. Associate Professor, Department of Educational Management, Isfahan (Khorasgan) Branch, Islamic Azad \\ University, Isfahan, Iran
}

\begin{abstract}
The general aim of the study is the identification of the managerial behavior components for the purpose of offering a model regarding the Iran's higher education system. Forty managers from the universities around Iran, including the directors and their vice presidents from the all types of universities have been asked to take part in the study. The data analysis was conducted through taking advantage of the qualitative background or grounded theory methodology and in the section on the causal conditions one of the subject matters obtained of the interest in the present study was the managerial behavior psychological basis. In regard of the psychological principles, eight general concepts were formed which are as follows: personality, intelligence, memory, aptitude, motivation, perception, emotion and stress. Generally, the findings indicated that in order for the managers to be equipped with managerial behavior they are in need of having thorough and proper studies and researches regarding the aforementioned components and try to handle tasks such as rethinking, restructuring and recreation of the components just cited.

Keywords: Management Psychological Principles, Management Psychology, Behavioral Psychology, Behavioral Psychology Foundations.
\end{abstract}

\section{Introduction}

The study and investigation of the human behavior is not(Ajzen, 2011; Winch, 2002), on the one hand, a new idea; neither, on the other hand, is it a subject matter that can be stripped of its booming and dynamicity and the human behavior is constantly undergoing investigation and scrutiny in various aspects and areas and it is such studies that pave the way for new inquiries and researches. Unscientific or non-systematized study and survey of the behavior takes a general format and it may be based upon the premises of one's own personal experience or as tried by the other individuals and it can be claimed that all of the human beings somehow deal therewith(Teger, 2017); that is, all the individuals observe and investigate whatever is performed by the others and try to make their own explanations, interpretations and predictions. But the scientific and systematized study is of a far greater importance and it is completely laid upon the foundation of scientific and precise research. The systematic study of the human behavior leads to the improvement in the ability to explicate, elaborate, predict, control and also guiding and changing the behavior and it unravels the interrelationships between the behaviors and the important realities, as well, resulting in providing for a basis for precisely predicting the human behavior(Griffin \& Moorhead, 2011; Hersey, Blanchard, \& Johnson, 2007).

One of the areas in the study of the human behavior which is also of an extraordinary significance is the area of management and organization. There is a plethora of extensive and comprehensive studies on organizational behavior and these studies commonly encompass a vast

To cite this paper: Kalantari, M., Baharestan, J.,\& Nadi, M. (2019). The Qualitative Analysis of the Managerial Behavior Psychological Foundations in Iran's Higher Education. Iranian Evolutionary and Educational Psychology Journal, $1,2,96-111$. 
area of the research. But, there are not reported many studies on managerial studies and it seems that there is a need for doing an extensive research in this area. With a psychological approach, the managerial behavior can be defined as "a relatively stable system of thoughts, emotions and potential and actual acts taken by the managers for the purpose of creating appropriate conditions in order for the activities to be carried out in line with the organizational objectives." In other words, it is the collection of the knowledge, discretion and competencies or the system of the thoughts, emotions and the activities that the managers potentially and actually need in line with creating appropriate conditions such as planning, organizing, guiding, coordinating and controlling for the human resources activity by taking advantage of the material, financial and informational sources parallel to the actualization of the organizational objectives.

Psychological foundations of the managerial behavior deals with the application of the psychology findings within the realm of management and it, in fact, analyses the individual's general behavior discussions as proposed in psychology within specialized managerial behavior topics which are both related to the science of psychology and science of management(Ones, Anderson, Viswesvaran, \& Sinangil, 2017; Safara, Keshavarz, \& Salmabadi, 2015).

Psychology is the science of studying the individual behavior, but in managerial behavior, it deals with the study of the managers' behaviors. Management is beyond whatever the behavior expected from the manager and it should not be by any means confined to the managers' individual endeavors, management is a lot more extensive than the manager's individual potency and the managers can only be said to be enjoying the necessary far-sightedness when they are not seeking to search their management vista inside their own existence and it is based on such an attitude that accomplishments can be attained in implementing the policies and plans based on the sagaciousness(Chiocchio, Kelloway, \& Hobbs, 2015; Gonder-Frederick, Shepard, Grabman, \& Ritterband, 2016).

The survey of the studies related to the managerial behavior and its psychological foundation is reflective of the idea that a body of extensive research is lacking in this regard and the studies which have been performed up to the present time are all conducted based on quantitative methodologies(Hodgkinson \& Healey, 2011; Powell, Lovallo, \& Fox, 2011). Therefore, performing qualitative studies regarding the managerial behavior and its psychological foundation is deemed necessary. Among the other reasons indicating the necessity and importance to conduct such studies is the value given to the management, managerial behavior and the managerial researches and studies in the universities and research and education institutions. Activating the thoughts within the context of the societies requires correct management and proper and principled managerial behavior based on the scientific findings and such type of active and scientific management and managerial behavior, particularly in the universities and research and education systems, is completely envisaged as necessary. Another reason is that studying the managerial behavior psychological foundations provides for the opportunity to get acquainted with the principles, rules and technological premises of correct deployment of the human resources, the methods of urging the creativities to blossom and creation of intellectual streams in the universities and educational systems and thus the barriers to the development in active cultural and educational systems and, resultantly, the barriers to the social, economic, political systems etc. can be removed through taking advantage of the psychological findings in this regard. It is via the promotion of such a managerial behavior based 
on the psychological principles, especially in university and education and research institutes, that the later generations' fertility can be accomplished and their creativity can be used as the most gigantic national capital.

The present study with its general title of the identification of the managerial behavior components aiming at presenting a model to be used by Iran's higher education system is seeking to make use of the underlying theory of qualitative methodologies, in the section on the causal conditions or the reasons and factors behind certain managerial behavior, to deal with the investigation of the managerial behavior psychological foundations and after providing a short summary of the study statements these psychological foundations and principles are going to be compared with one another in order for more general concepts to be formed and then to be integrated under a more general categorization class and this is the theme which is classified under the managerial behavior causal conditions in Iran's higher education system.

\section{Theoretical principles and theoretical literature}

Psychology is the study of human behavior or better said it is the scientific study of the behavior. This field of study has many specialized branches, some of which are related to the science of psychology termed experimental psychology. The other branches are connected to the applied aspects of the principles and the scientific findings of the psychology which are termed applied psychology. In the organizations and in the study and survey of the managers and staff behavior the applied branch of psychology is more accentuated(Cooper, 1991; Riggio \& Porter, 2017; Spector, 2008).

Scientific psychology is seeking to assess, justify and enumerate the reasons and causes and sometimes it is looking for changing the individuals' behaviors. The psychologists have continuously been in pursue of investigating the individual behavior and try to gain a clear understanding thereof(Petrou, Demerouti, \& Schaufeli, 2018). In the organizations and in relation to the managers and the staff, the learning theoreticians, experts in personality, clinical psychologists and more importantly industrial and organizational psychologists have played a pivotal role. In the past, the industrial and organizational psychologists have dealt with issues such as fatigue, dullness and other factors in connection to the working environments that might be a cause of reduction in the individuals' efficiency. Later on, they tried to deal with such subjects as the thoughts, perceptions, personality, learning, education, effective leadership, motivational needs and forces, job satisfaction, decision-making process, performance evaluations, attitude assessment, staff selection methods, job planning and work tensions(Hersey et al., 2007; Kinicki \& Kreitner, 2006).

The studies pertaining to the managerial behavior psychological foundations not only propel the manager to take advantage of the psychological findings in solving the problems and issues and deal with the analysis of the managerial behavior through making active use of the theories therein, but they also enable the manager to deal with the survey and recognition of the weak and strong points and consequently become in the possession of a stronger managerial behavior through corroborating the strong points and by covering the weak points.

Luthans (2002) in a study called "Positive organizational behavior: Developing and managing psychological strengths" investigated the positive psychology application in the realm of organizations and management. The components of the positivistic organizational behavior include happiness, hopefulness, optimism, generosity, appraisal, self-efficiency, encouragement 
and stubbornness.

Lu (2011) undertook a study called "the evaluation of the extensive competencies of the organizational human resources based on managerial psychology and made use of the main management, psychology concepts in human resources management based on its four main parts which are the selection, employment, apprenticeship and retention talents. Then, corresponding to the above-mentioned ideas the organization's considerable human resources, competencies evaluation index system was created and dealt with the development of the organization's human resources, extensive competencies evaluation index system through taking advantage of the analytical hierarchy process.

Nuthall (2001) in a study entitled "managerial competencies- the improvement of its foundation and potential through making use of the psychological concepts" tried to focus mostly on acquiring a full understanding of the managerial competency components and the managers' ability for making use of and improving such competencies as compared to their previous statuses. Also, psychology focuses on decision-making and finally it comes up with expressing the fact that psychology proposes suggestions for changing the personality characteristics and how it can be helpful in improving the individuals' managerial ability.

Marchant et al. (2009) conducted the study "mental strength, managerial differences and age". The objective of the study was to survey if the staff in various managerial levels (for instance, senior, medium and low) exhibits various levels of stubbornness. The results reveal substantial, significant effects in connection to both of the variables, position and age. Next, the analyses indicated that the stubbornness rate in more senior positions and higher ages was higher. The results of the study showed that stubbornness can be developed and enhanced via holding appropriate apprenticeship programs.

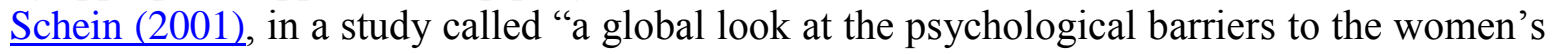
progress in management", based on a research that had been undertaken at early 1970s in the US and had resulted in the finding that the gender is a giant psychological barrier on the women's progress way in management and because of the value given to management globally, the survey of the relationship between the stereotype or cliché behaviors, it was concluded that gender and management attributes are of a great importance and in fact they play an essential role. The study performed by Schein embraced a variety of countries including the US, Great Britain, Germany, China, and Japan and it laid the foundation of reaching to a global look at the phenomenon of the "manager's thought-the man's thought". The results are suggestive of the idea that the women's progress in management has to be followed with outcomes, especially among the men, which can be discussed.

\section{Material and Methods}

The grounded theory, method has been used in the present study, which is a qualitative method. Grounded theory was introduced by Glaser, Strauss, and Strutzel (1968) with the publication of the book "discovery of the grounded theory" to the scientific society and it was greatly welcomed. Grounded theory is an assumption which is directly deduced and extracted from the data which have been collected and analysed regularly and in an organized manner during the course of carrying out the research. In this method, the data collection method, analysis and the proposition of the final theory are closely interrelated. In this method, the 
researcher does not start the study by crystallizing a prior theory in his mind (unless he is aimed at expanding a previously extant theory); rather, the study work is launched in the reality area and the researcher allows the theory to emerge from inside the data collected(Strauss \& Corbin, 1998). One of the common approaches in the grounded theory is the Objectivist approach proposed by Strauss and Corbin (1990) and (1998) which is comprised of orderly regular and analytical processes. Such an approach takes advantage of paradigmatic patterns to organize the findings and augment their power of elaboration which is, allegedly, consisting of five parts: 1. Causal conditions, 2. Background conditions and intervening factors, 3. Strategies, 4. Outcomes, and 5. Central theme or the core subject(Neuman, 2013; Patton, 2005).

Participants: The study participants included forty of the managers from the country's university comprising of the rectors and their vice presidents from the state, Azad, teacher training, Payem-e-Noor and nonprofit universities. Selecting the university managers and their participation has been carried out with the purpose that the study subject matter is the identification of the managerial behavior components aiming at the presentation of a model for Iran's higher education system and based on the current study subject matter, the university managers were considered as satisfying and appropriate for getting them to participate in the present study.

Sampling: In the present study we have made use of theoretical sampling methods to select the participants. Theoretical sampling is a sort of data collection, which is conducted based on the evolving concepts. Theoretical sampling is based on the concept of comparison, by comparison here we mean that one should look for places, individuals and the incidents in which the likelihood of discovering the diversities and varieties is at its maximum and the subjects can be enriched with the plenty of attributes, traits and dimensions. Theoretical sampling is conducted based on snowballing or cumulative method. Every event which is taken into consideration as a sample originates from prior data and analysis and will be added to the main body of the information. The more the sampling advances, it turns into something more specific that is because it guides and navigates the analyst-formed theory. In the early sampling the researcher is interested in getting the most ideas possible; for the same reason, the researcher tries to gather the data from the vast areas of research relevant to his or her work. But, the sampling is performed purposefully as soon as a number of ideas are obtained and the sampling is continued with the objective of flourishing and satiating the ideas(Strauss \& Corbin, 1998).

Data Collection: The data collection, data analysis and the final theory are all interconnected in the grounded theory method(Strauss \& Corbin, 1998). Semi-structured interview has been the most used technique in the data collection phase of the present study. Firstly, the interview questions or the interview guidelines are prepared based on the study objectives and then the semi-structured interviews are initiated, accordingly and in the course of data collection, the interview guidelines are replaced by the concepts extracted from the data and this is the process which is iteratively continued up to the theoretical saturation.

Data Analysis: The main structure of the data analysis in the grounded theory, method is based upon three coding styles: 1. Open coding, 2. Axial coding, and 3. Selective coding. The researcher deals with producing the ideas and generating the features through making use of the open coding. In axial coding, the ideas are flourishing and fostered based on a regular procedure and their relationships to the subcategories are figured out and the selective coding is used to aim 
at the integration and purging the subject matters and ideas(Strauss \& Corbin, 1998).

Variable evaluation: To reach to a trustworthiness scale, three following techniques are used: firstly, member check evaluations in which the participants are asked to assess the general findings and opinions about the trustworthiness and accuracy thereof. In the second method, that is the analytical comparison, the raw data are taken into consideration in order for the material structure and configuration to be compared and, consequently, compared with the raw data and, thirdly, by making use of the auditing technique, several experts are asked to supervise the conceptualization and the information extraction processes in various coding stages in the grounded theory job.

\section{Results}

In this section, the data analysis results are presented based on the threefold coding stage. Data analysis was conducted based on Microanalysis and line-by-line methods. After the concepts were concisely extracted from the propositional statements, they were compared and the relevant concepts and ideas were integrated under a more general concept called topic. The general topic of the current study is the identification of the managerial behavior indicators aiming at the presentation of a model for the Iran's higher education system and it is worth mentioning that the current study makes use of the grounded theory in the qualitative section herein and one of the ideas related to the causal conditions or the reasons and factors behind managerial behavior in the present study is the idea of managerial behavior psychological foundation in Iran's higher education system. Such an idea is consisted of eight components which cover the entire array of the partial concepts related to the idea. Table (1) presents the data analyses results within the threefold coding stage in connection to the managerial behavior topic.

Table 1. The results of the threefold open, axial and selective coding stage

\begin{tabular}{|l|l|}
\hline Subject & Concepts \\
\hline personality & $\begin{array}{l}\text { Personality, personality characteristics, individual differences, self- and others' recognition, seeking } \\
\text { promotion outside the normal frameworks, others' defamation, feeling of inferiority before one's own }\end{array}$ \\
superior and feeling superiority before one's own subordinates, seeking for pure discrimination in \\
one's subordinates, the qualified and competent individuals' isolation and the incompetent and \\
disqualified individuals' misuse and abuse of the conditions, meritocracy, acquiring the scientific \\
principles, being practical, prejudice, malevolence, distrust, self-directedness and narcissism, \\
dependence, complicacy, preferring one's own self-interests, profit-centeredness, reaching to one's \\
own objective at any cost
\end{tabular}




\begin{tabular}{|c|c|}
\hline & and for the others' advantage \\
\hline Aptitude & $\begin{array}{l}\text { Talent, readiness , preparation, abilities, capacities, potentials, competencies, speed in taking actions, } \\
\text { accuracy, timeliness, postponing the jobs, magnification of one's own tasks, giving more importance } \\
\text { to one's own duties, giving less value to the others' duties, slackness, lacking the necessary skills, } \\
\text { slow promotion path, lacking the ability to work with the others, being inattentive to one's own and } \\
\text { the others' talent development }\end{array}$ \\
\hline Motivation & $\begin{array}{l}\text { Motivation, incentive, tendency, willingness, interest, enhancement, reward, punishment, encourager, } \\
\text { threat, reproach, humiliation, defamation, attention, imbalance, tension, needs, expectations, } \\
\text { prevention from reaching to objectives, improvement and growth, increasing the responsibilities, self- } \\
\text { satisfaction, being admired, ambitiousness, determining participatory objectives, financial and } \\
\text { nonfinancial motives, the absence of a proper motivational system, substitution of the misuse and } \\
\text { abuse system }\end{array}$ \\
\hline Perception & $\begin{array}{l}\text { Perception, feeling, thoughts, conception, social understanding, organizational perception, managerial } \\
\text { conception, staff understanding, being faced with ambiguous situations, cliché contacts, subjectivism, } \\
\text { putting oneself in the others' shoes or empathy, inquiring about the way the others perceive, very high } \\
\text { or very low expectation levels, high expectation of low level individuals, low expectation of the high } \\
\text { level individuals, mental moods, self- and others' imagination, recognizing and recording one's own } \\
\text { deviations and taking steps to change them, strict and baseless fanaticism, commitment imagination, } \\
\text { pretending commitment and misusing it, considering success as stemming from one's own efforts and } \\
\text { failure as resulting from the others' efforts, prejudgment }\end{array}$ \\
\hline Emotion & $\begin{array}{l}\text { Emotion, emotion control, emotion management, emotional intelligence, fear, anger, wrath, love and } \\
\text { prejudice, affections, feelings, sowing hatred, pure obedience, unquestioned submission, defamation, } \\
\text { making reports, extreme ecstasy for successes, high level of frustration and disappointment in failures, } \\
\text { negative emotions and reactions to change, being incapable of controlling the emotions when } \\
\text { questioned, inappropriate treating of the opposite ideas, aggressiveness, pessimism, rejecting and } \\
\text { denying the others' ideas }\end{array}$ \\
\hline Stress & $\begin{array}{l}\text { Stress, mental pressure at work, stressful situations, feeling of worthlessness, lack of joyfulness, } \\
\text { mental weakness, unwilling to do a job, hurriedness and retardation, disharmony at work and at } \\
\text { organization, lack of confidence in one's own self- and others', imbalance in speaking, vocational and } \\
\text { organizational conflicts, increase in the heart rate, respiration and sweating, pleasant mental pressure, } \\
\text { daily pressures, programmed unfavorable pressures, everyone's not being their right place, individual } \\
\text { and organizational lying, impatience, aggression, tranquility upon remembering the God }\end{array}$ \\
\hline
\end{tabular}

Personality: A review of the definitions provided by the psychologists indicates that in spite of the diversions in offering the personality definitions, five common features can be underlined:

1. Universality: personality is a general idea comprised of the constituent components which is different from the collection of the single components and it is an inference phenomenon, very much like intelligence.

2. Integrity: personality components are intertwined in such a manner that a single organization is created via their unification.

3. Dynamicity: the personality components exert force on one another.

4. Stability: the behavioral patterns stay stable during the course of time. Therefore the behavior can be predicted.

5. Individuation: The personality evolution path in an individual is in line with the individual's becoming distinguished from the others.

Therefore, personality can be defined as a dynamic and relatively stable system which distinguishes the individual from the others and provides for the relative prediction of the individual's behavior in certain situations(Chamorro-Premuzic, 2016). 
In order to be able to enjoy a strong managerial behavior, the managers should take advantage of the findings obtained in various and extensive researches and studies concerning personality and the theories proposed regarding personality such as Hippocrates and the four types of temperaments in the human body including, sanguine, choleric, melancholic, and phlegmatic; Galen and the prevalence of the fourfold temperament such as the choleric, phlegmatic, sanguine and melancholic; Freud and his topographical model of personality including self-conscious, semi-conscious and unconscious and the personality structural model including the id, ego and superego; Jung and the personality structure and the introvert and extrovert personality characteristics and the functions of the feelings, intuition, affection and thoughts the combination of which with the personality types and functions generates eight personality types; Adler (2013) and the principle of inferiority, the principle of seeking for superiority, life style, selfconsciousness, social interest, ultimacy and life goals and the creative self; Sheldon and Stevens and the hedonisms, activists and thinkers; Eysenck and the introversive-extroversive personality characteristics and neuroticism, the theories of the thin films including the locus of control, Machiavellian personality, the theories based on five personality characteristics including extroversion, agreeableness, $\mathrm{F}$ and the authoritarian or type A personality, conscientiousness, emotionally stable and openness to experience, the theory of the control locus personality characteristics, despotism, Machiavellianism, adaptation to the environmental factors and risktaking; Holland and the theory of the personality-job fitness including the realistic, investigative, social, conventional, enterprising and artistic personality traits; Lewin (2013) and his field theory of personality, the energy field analysis and the process of change; Mary and the human personality theory and the various types of the needs, Allport (1937) and the traits theory; Ericson and the personality growth stages, Argyris (2004) and the theory of maturity and immaturity and so forth and the managers should put such a knowledge into practical use in the organizational environment and in the interaction with their own selves and the others.

Intelligence: There is no single definition proposed for the term intelligence and various specialists define it differently. However, there are elements of the intelligence that are generally agreed upon by the majority of the researchers. Berliner and Calfee (2013) have classified these elements into three categories:

1. The ability to handle abstract issues: it means that the intelligent individuals are more dealing with the abstract issues (thoughts, symbols, relations, concepts and principles) than working with objective issues (mechanical implements and sensory activities).

2. Problem-solving ability: that is the ability to deal with new situations, not only giving pre-learnt responses to familiar situations.

3. The ability to learn: particularly learning abstract ideas including the abstract meanings of the words and the other symbols and also the ability to make use of such things.

Study and analysis and the application of the various theories put forth regarding intelligence including the ideas proposed by J. P. Guilford (1967) and (1988) and the intelligence structure pattern (intellect structure) involves three parts of operation (cognition, memory and recalling, divergent production, convergent production and evaluation), content (visual or figural, symbolic, semantic and behavioral) and products (units, classes, relations, systems, changes and implications); Sternberg (1985), (1997), (2000) and the three-part intelligence theory including analytical intelligence, creative intelligence and the practical intelligence; Gardner (2011), 
(2003) and the ,multiple intelligence theories including verbal intelligence (linguistic), musical intelligence, logical-mathematical intelligence, spatial intelligence, bodily-kinesthetic intelligence, naturalist intelligence, perception of the others (interpersonal intelligence) and selfperception (intrapersonal intelligence); Goleman (2006) and emotional intelligence including five parts of self-consciousness, self-regularization, motivation, empathy and social skills; Cattel and the fluid intelligence and the crystallized intelligence and so on can all be of a considerable contribution to the managers' behavioral enhancement.

Memory: John Robert Anderson (2000) defines memory as a relatively stable record which forms the basis of learning. The most important term which is of a remarkable importance in the above definition is "record". The terms "record" is reflective of the changes and variations which take place along with learning and are therefore recorded and stored. Physiological psychologists believe that memory is a term used to make a reference to the hormonal and neural changes therefore it has to be considered as something well beyond the mere registration and storing of the information. Cognitive psychologists are of the belief that memory is the locus the information is processed, thus storing and maintaining the information is only one stage of the memory numerous stages and it has been found that there are factors which are constantly influencing the way the information is processes the effects of which shapes the memory(McDaniel, 2013).

It is through appropriate studies and taking advantage of such researches and the relevant theories to the memory including Atkinson and Shiffrin (1968) and three-stage theory of news processing encompassing the sensory memory, short-term memory and long-term memory; Tulving (2002) and the theory of various long-term memory embracing the procedural memory, perceptive memory, semantic memory and incident memory; Squire and declarative and executive memories; Graf and Schacter (1985) and explicit and implicit memories; John R Anderson and Bower (1974) and their theory of two-process recalling involving the production and recognition; Craik and Lockhart (1972) and their theory of the processing levels; Paivio $\underline{(1990)}$ and the theory of binary code including the verbal information and the mental images; Lewandowsky and Murdock Jr (1989) and their theory of parallel distribution process; Bates and Elman (1993) and their theory of connectionism and so forth that the managers can analyze their managerial behavior and contribute to its growth and corroboration.

Aptitude: It can be said that aptitude includes the natural preparation or non-acquired readiness for carrying out some of the tasks, that is to say if the individuals are put in identical educational conditions they will exhibit differences, the reason behind such differences is what we call aptitude or talent (Furr, 2017). Bloom (1968), (1976) and Carroll (1963) determined the ability to learn and acquire knowledge by means of aptitude. Carole defines talent as the time required by the individual (learner) to learn a subject or acquire a skill.

It is through the investigation, study and application of the aptitude-related theories including Thurstone (1938) and the preliminary factors of talent such as verbal talent, verbal-fluid, figural, spatial imagination, memory, perception speed and reasoning; Spearman (1927) and the general talent factors or the general aptitude and specific factors such as mechanical talent, logical talent, spatial talent and mathematical talent, etc. that the managers can help the employees' talents and their own aptitude grow and this is how they can improve their managerial behavior.

Motivation: Motivation is a term used to refer to the creative, maintaining and guiding forces of 
the behavior. In the meantime, motive has been defined as a special need or will which brings about the condition for the motivation. Motivation and motive have been mostly used interchangeably. However, motive can be realized as being more precise than the motivation as far as it is concerned in respect to the main theme of the current study; in such a manner that motivation is considered as the general factor causing behaviors to be generated by the individual but motive is the specific reason behind certain behavior exhibited by the individual. Concepts such as need and drive find greater importance in respect to the motivation. Need is the term which is commonly used to point to a state resulting from a lack or deprivation in the living creatures and the drive is the energy or the tendency coming out of the need(Seif, 2008).

Management activities effectiveness depends highly on the individuals' tendencies inside an organization. On the other hand, the individuals' entire array of the behaviors is objectiveoriented and purposive. In this regard, there are two sets of factors forming the individual's behavior, one is the motive and the other is the goal. Therefore, motivating the individuals to accomplish their organizational assignments and their individual goals being in line with the organizational objectives plays an essential role in the organizational success.

If the managers are seeking to attain effective and efficient managerial behavior they have to firstly gain knowledge of the motivation and the theories related thereto including the theory of needs hierarchy, $\mathrm{X}$ and $\mathrm{Y}$ theory, the theory of hygiene-motivation, the theory of the three-fold needs or the acquired needs, the theory of the objective determination, the theory of behavioral enhancement, the theory of equality, the theory of expectations, the theory of objective-based management, behavior adjustment, staff participation, plans and programs in respect to variable consideration, the theory of various life stages, the theory of biological needs, belonging and growth, the theory of equality, the theory of expedient pattern of motivation and so forth, and, secondly, they are required to make use and apply such type of knowledge in order to make themselves and the employees motivated and in order for a proper motivational atmosphere can be created.

Perception: Everyone sees the world through various perspectives(Baron \& Greenberg, 1990). The process of receiving, interpreting and the rendering of the environmental stimulus is called perception. The individual's behavior is formed on the basis of the interpretation and the rendition the person makes of the reality s/he is bearing witness to; that means that the person's behavior is based on his or her perception of the reality not the reality itself. Most of the individuals are ignorant of the point that the reality which is perceived by them is different from the reality which is conceived by the others. The perceptional process is consisted of three major parts: sensation, attention and perception. Sensation: a numerous number of the environmental stimulants surround the person at any single point in time and the individual is unconscious of a great many of them; since the individual has, on the one hand, learnt to ignore them and, on the other hand, the individual's sensory organs are incapable to sense and receive all of them. Attention: although the human beings are capable of sensing a great many of the environmental stimulants but they pay attention to a small fraction of these stimulants and ignore the rest. Perception: the perceptional process is responsible for organizing, interpreting and rendering the individual's sensations( Hersey et al., 2007).

The study, survey and the analysis of the perception-related ideas and theories including the ideas proposed by Merton and his theory of superego satisfaction, the theory of attribution and 
the theory of perception and the effective management and so forth play a significant part in understanding and applying perception in management and cause the managerial behavior to be based upon the perceptions of the others, ones' own selves and the organization.

Emotion: Nowadays, the psychologists have learnt a lot about the importance of the emotions in many of the different behavioral areas such as logical decision-making and objective-oriented behavior (Hockenbury \& Hockenbury, 2010). Emotion is a sensational state of mind which is comprised of the threefold physiological, cognitive and behavioral component. Intensive emotions cause arousal in the autonomic nervous system and the higher the arousal the intensity of the emotions will be higher. Apparently, the term emotion has something to do with the feelings and senses and it is not related to the thoughts, but the cognitions and especially the interpretations made of the meanings given to the incidents and events involve a critical aspect of the emotion. Emotions also include the behavioral inclinations and propensities.

Having a clear understanding and knowledge of the emotions and the theories related thereto including the theory proposed by James-Lange, the theories put forth by Cannon-Bard, the cognitive labeling theory presented by Schachter and Singer (1962), Solomon and Corbit (1978) theory of opponent process, the theory of cognitive evaluation by Lazarus, the theory offered by Zajonk, Mesquita and Frijda's intercultural theories and so many others contribute the managers to discern the exact nature of the emotions and in this way they can be assisted to accompany their managerial behavioral with emotions control in respect to their own selves and those of the others.

Stress: Stress or the mental pressure is a phenomenon which has been found to exert an extensive effect on the organizational climate, human interrelations and the mental hygiene in the today's communities and the novel organizations. Stress, in itself, is not a bad thing at all and it can also possess positive values. When this phenomenon is found to be having positive effects it is seen as opportunities and chances(Fredrickson, 2001).

Selye (1987) defines mental and stressing pressure as "the mental pressure or stress which includes the physiological response of the human body to any type of mental or physical adjustment request" and the pressure-makers or the stressors are the mental or the physical adaptation demands and requests made by the human body. Different individuals demonstrate various reactions to the mental pressures and the human body's response to the mental pressure includes physical, psychological and behavioral systems.

The managers should make use of the studies and researches performed regarding the mental pressures and the mental pressure theories proposed including the theories of the life incidents, the theory of general adaptation syndrome, the theory of the type A and type B personalities, the theory of cognitive evaluation of the stressing situations, the theory of control, the theory of social support, the theories of psychological stubbornness and sense of humor and so forth to strengthen their managerial behavior in confrontation with the mental pressures existing in the organization and they should accompany their own managerial behavior with the extant mental pressure management methods.

\section{Discussion}

In a research with the general title of "the identification of the managerial behavior components for the purpose of offering a model for Iran's higher education system", we have 
made use of the grounded theory method, Strauss-Corbin approach in the qualitative section. The approach is composed of five parts: 1. causal conditions, 2. background and intervening conditions, 3. strategies, 4. outcomes and 5. the central theme or the subject matter; additionally, in the section in the causal conditions or the reasons and factors part of the present study, one of the subject matter which was formed was the psychological foundations of the managerial behavior. After the concepts and ideas were extracted from the statements proposed in the current study, they were compared with one another and eight general topics were formulated all of which were integrated under the subject of psychological foundations.

Personality: In order for the managers to enjoy the managerial behavior they are required to undertake extensive research on personality, concepts related to personality, the way personality is shaped, the factors effective on the creation of certain type of personality, personality growth, personality disorder, personality assessment, personality features, job-personality fitness, personality theories and so forth and through attaining a full understanding of the topics and titles mentioned above the managers can satisfy their sense of curiosity and tendency to seek for the truth and realities, that is because such a knowledge is some sort of self-recognition in the process of which the manager will get to know oneself. Moreover, such recognition allows the manager to adopt appropriate and conscious standpoint in respect to the others and devise contingent preventive measures in case that disorders and disarrangements occur.

Intelligence: The managers can deal with the enhancement of their intelligence quality, and the intelligence quality of their human resources and the organization as a whole and act well beyond their intelligence ability and exhibit a performance in a much higher level than their intelligence ability allows and this way they can be equipped with far stronger managerial behavior, all of which can be accomplished through gaining a higher knowledge and recognition of the intelligence-related topics, single unitary intelligence and multiple intelligence, intelligence quality, intelligence training, various aspects of intelligence, intelligence evaluation, intelligence theories and so forth. Furthermore, the managers can augment and corroborate their strong point and mask their weak points in respect to the intelligence-related ideas and topics in this way.

Memory: studying on memory, the memory-related concepts, stages of memory including coding, storing and accumulation and retrieval, types of memory, methods of recalling and recognition, forgetfulness, memory improvement methods, theories on memory and so on can bring about a condition for the managers' behavioral enhancement. Also, the managers can take advantage of the memory corroboration strategies such as reviewing and repetition in appropriate time intervals, organizing the subject matters and establishing reasonable relationships between them, mental imaging for objectify the abstract concepts and generalizing a system of the components and parts and so forth contribute to the enhancement and strengthening of their own memories and the memories of the others and the organization as a whole, thus they can become in possession of a far more efficient managerial behavior.

Aptitude: There are numerous experimental evidences and abundant educational theories indicating that environmental enrichment is effective on fostering one's own aptitudes and talents and factors such as age, education and upbringing, exercise and gender cause the talents and aptitudes to change. Through considering this principle as a rubric to be followed and through making thorough analyses of the talents, aptitude-related concepts, aspects of talents, the 
factors changing the talents' structure, talent and aptitude-related theories can contribute to the talent development in their employees and in themselves and this way they can improve their managerial behavior.

Motivation: In case that the managers are looking for ways to get to the efficient managerial behavior and then put it into practical use, they are required to gain a full understanding of motivation, motivation-related concepts, motivational processes, motivational theories and so forth and then the proper motivational atmosphere can be more readily made available inside the organization.

Perception: Perception and the perceptional process are of a great importance, since the individuals behave based on the way the perceive environment and conditions and various individuals have different perceptions of the world they are living in. Perceptional processes play a significant role in management decision making regarding the issues such as making selections, appointment and promotions concerning the employees. Also, perception has been found to be playing a great part in the performance evaluation process. In the meantime, perceptional recognition can contribute to the managers' ability in oral or written communications with the employees. Therefore, the studies performed on the perception, perception-related concepts, perceptional processes, perceptive organization, social perception, perceptional mistakes, theories proposed regarding perception can be helpful in specific understanding and application of the perception in the managerial behavior.

Emotion: Many of the managers who enjoy an array of great many of the qualifications cannot perceive the others' emotional responses and respond appropriately to their emotions as a result of not being capable of managing and controlling their own emotions, therefore they cannot achieve great accomplishments. In order for the manager to be enabled to have strong managerial behavior it is necessary to perform appropriate and sufficient studies on emotion, emotion-related concepts, major emotions, expression of emotions, theories on emotion and so forth and it is through conceiving the nature of the emotion that the manager can handle the management and control of the extant emotions and this way the managerial behavior can be enhanced.

Stress: To cope with the mental pressure and manage stress, the managers should have appropriate and sufficient knowledge of the mental pressure and stressors, mental pressure at work, symptoms of the mental pressure, the factors contributing to the mental pressures, vocational pressure consequences, strategies helping in fighting with the mental pressures, mental pressure theories and so on and it is through making practical use of such knowledge that not only the creation of negative mental pressure at work environment can be inhibited and such negative pressures can be controlled and managed, but an atmosphere replete with positive mental pressure can be generated.

As regarding the topic of psychological foundations of the managerial behavior in Iran's higher education, the findings, generally, indicated that there are eight general concepts which have been found to have a remarkable significance and the managers should conduct extensive and appropriate studies in areas such as personality, intelligence, memory, aptitude, motivation, perception, emotion and stress in order to become capable of showcasing strong managerial behavior. Extensive research, which is simultaneously up-to-date and continuous, on the abovementioned eightfold area can be of a considerable contribution and assistance to the managers in 
rethinking, reconstructing and recreating of such areas and cause the managers to enjoy a far stronger and more efficient managerial behavior in respect to the psychological foundation of the managerial behavior.

\section{References}

Adler, A. (2013). The practice and theory of individual psychology (Vol. 133): Routledge.

Ajzen, I. (2011). The theory of planned behavior: Reactions and reflections. Psychology \& Health, 26(9), 1113-1127. doi:10.1080/08870446.2011.613995

Allport, G. W. (1937). Personality: a psychological interpretation. Oxford, England: Holt.

Anderson, J. R. (2000). Learning and memory: An integrated approach: John Wiley \& Sons Inc.

Anderson, J. R., \& Bower, G. H. (1974). A propositional theory of recognition memory. Memory \& Cognition, 2(3), 406-412.

Argyris, C. (2004). Immaturity-maturity theory. Management oforgani zat iona, 1.

Atkinson, R., \& Shiffrin, R. (1968). Human Memory: A proposed system and its component processes. The psychology of learning and motivation: New York: Academic Press.

Baron, R. A., \& Greenberg, J. (1990). Behavior in organizations: Understanding and managing the human side of work (Vol. 1): Allyn \& Bacon.

Bates, E., \& Elman, J. L. (1993). Connectionism and the study of change. Brain development and cognition: A reader, 623-642.

Berliner, D. C., \& Calfee, R. C. (2013). Handbook of educational psychology: Routledge.

Bloom, B. S. (1968). Learning for mastery. Evaluation comment. Center for the Study of Evaluation of Instructional Programs, UCLA.

Bloom, B. S. (1976). Human characteristics and school learning: McGraw-Hill.

Carroll, J. B. (1963). A model of school learning. Teachers college record.

Chamorro-Premuzic, T. (2016). Personality and individual differences: John Wiley \& Sons.

Chiocchio, F., Kelloway, E. K., \& Hobbs, B. (2015). The psychology and management of project teams: Oxford University Press.

Cooper, C. L. (1991). Industrial and organizational psychology: Edward Elgar Publishing.

Craik, F. I., \& Lockhart, R. S. (1972). Levels of processing: A framework for memory research. Journal of verbal learning and verbal behavior, 11(6), 671-684.

Fredrickson, B. L. (2001). The role of positive emotions in positive psychology: The broadenand-build theory of positive emotions. American Psychologist, 56(3), 218.

Furr, R. M. (2017). Psychometrics: an introduction: Sage Publications.

Gardner, H. (2003). Multiple intelligences after twenty years. American Educational Research Association, Chicago, Illinois, 21.

Gardner, H. (2011). Frames of mind: The theory of multiple intelligences: Basic books.

Glaser, B. G., Strauss, A. L., \& Strutzel, E. (1968). The discovery of grounded theory; strategies for qualitative research. Nursing research, 17(4), 364.

Goleman, D. (2006). Emotional intelligence: Bantam.

Gonder-Frederick, L. A., Shepard, J. A., Grabman, J. H., \& Ritterband, L. M. (2016). Psychology, technology, and diabetes management. American Psychologist, 71(7), 577. 
Graf, P., \& Schacter, D. L. (1985). Implicit and explicit memory for new associations in normal and amnesic subjects. Journal of Experimental Psychology: Learning, memory, and cognition, 11(3), 501.

Griffin, R. W., \& Moorhead, G. (2011). Organizational behavior: Cengage Learning.

Guilford, J. P. (1967). The nature of human intelligence. New York, NY, US: McGraw-Hill.

Guilford, J. P. (1988). Some changes in the structure-of-intellect model. Educational and Psychological Measurement, 48(1), 1-4.

Hersey, P., Blanchard, K. H., \& Johnson, D. E. (2007). Management of organizational behavior (Vol. 9): Prentice hall Upper Saddle River, NJ.

Hockenbury, D. H., \& Hockenbury, S. E. (2010). Discovering psychology: Macmillan.

Hodgkinson, G. P., \& Healey, M. P. (2011). Psychological foundations of dynamic capabilities: reflexion and reflection in strategic management. Strategic Management Journal, 32(13), 1500-1516.

Kinicki, A., \& Kreitner, R. (2006). Organizational behavior: Key concepts, skills \& best practices: McGraw-Hill/Irwin Columbus, $\mathrm{OH}$.

Lewandowsky, S., \& Murdock Jr, B. B. (1989). Memory for serial order. Psychological Review, 96(1), 25.

Lewin, K. (2013). A dynamic theory of personality-selected papers: Read Books Ltd.

Lu, J. (2011). Evaluation of Enterprise Human Resources Comprehensive Abilities Based on Managerial Psychology. Procedia Engineering, 16, 564-571.

Luthans, F. (2002). Positive organizational behavior: Developing and managing psychological strengths. The Academy of Management Executive, 16(1), 57-72.

Marchant, D. C., Polman, R. C., Clough, P. J., Jackson, J. G., Levy, A. R., \& Nicholls, A. R. (2009). Mental toughness: Managerial and age differences. Journal of Managerial Psychology, 24(5), 428-437.

McDaniel, J. W. (2013). Physical Disability and Human Behavior: Pergamon General Psychology Series (Vol. 3): Elsevier.

Neuman, W. L. (2013). Social research methods: Qualitative and quantitative approaches: Pearson education.

Nuthall, P. (2001). Managerial ability - a review of its basis and potential improvement using psychological concepts. Agricultural Economics, 24(3), 247-262.

Ones, D. S., Anderson, N., Viswesvaran, C., \& Sinangil, H. K. (2017). The SAGE Handbook of Industrial, Work \& Organizational Psychology: V3: Managerial Psychology and Organizational Approaches: SAGE.

Paivio, A. (1990). Mental representations: A dual coding approach: Oxford University Press.

Patton, M. Q. (2005). Qualitative research: Wiley Online Library.

Petrou, P., Demerouti, E., \& Schaufeli, W. B. (2018). Crafting the change: The role of employee job crafting behaviors for successful organizational change. Journal of Management, 44(5), 1766-1792.

Powell, T. C., Lovallo, D., \& Fox, C. R. (2011). Behavioral strategy. Strategic Management Journal, 32(13), 1369-1386.

Riggio, R. E., \& Porter, L. W. (2017). Introduction to industrial/organizational psychology: Routledge. 
Safara, M., Keshavarz, S., \& Salmabadi, M. (2015). The Moderating Effect of Job on the Relationship between Control Wrath and Mental Health in Extrovert Women. Academic Journal of Psychological Studies, 4(3), 66-72.

Schachter, S., \& Singer, J. (1962). Cognitive, social, and physiological determinants of emotional state. Psychological Review, 69(5), 379.

Schein, V. E. (2001). A global look at psychological barriers to women's progress in management. Journal of Social issues, 57(4), 675-688.

Seif, A. (2008). Modern educational psychology: Learning and teaching psychology: Tehran: Doran.

Selye, H. (1987). Stress: Sterling Educational Film.

Solomon, R. L., \& Corbit, J. D. (1978). An opponent-process theory of motivation. The American Economic Review, 12-24.

Spearman, C. (1927). The abilities of man. Oxford, England: Macmillan.

Spector, P. E. (2008). Industrial and organizational psychology. Research and.

Sternberg, R. J. (1985). Beyond IQ: A triarchic theory of human intelligence: CUP Archive.

Sternberg, R. J. (1997). Successful intelligence: First Agency Publishing.

Sternberg, R. J. (2000). Handbook of intelligence: Cambridge University Press.

Strauss, A., \& Corbin, J. (1990). Basics of qualitative research (Vol. 15): Newbury Park, CA: Sage.

Strauss, A., \& Corbin, J. (1998). Basics of qualitative research: Procedures and techniques for developing grounded theory: Thousand Oaks, CA: Sage.

Teger, A. I. (2017). Too Much Invested to Quit: Pergamon General Psychology Series: Elsevier.

Thurstone, L. L. (1938). Primary mental abilities.

Tulving, E. (2002). Episodic memory: From mind to brain. Annual review of psychology, 53(1), $1-25$.

Winch, P. (2002). The idea of a social science: And its relation to philosophy: Routledge. 